\title{
Physical activity, sedentary behaviours and eating habits among school children in kerala
}

\author{
John $\mathbf{M}^{1}$, Nihaz NK ${ }^{2}$, Jacob Cherian $V^{3}$ \\ ${ }^{1}$ Dr. Mini John, Associate Professor, Department of Paediatrics, P K Das Institute of Medical Sciences, Vaniamkulam, \\ Ottapalam, Palakkad, Kerala. ${ }^{2}$ Dr Nihaz Naha K, Postgraduate, Department of Paediatrics, Jubilee Mission Medical \\ College, Thrissur, Kerala, ${ }^{3}$ Dr Vinod Jacob Cherian, Professor, Department of Paediatrics, Jubilee Mission Medical \\ College Thrissur, Kerala.
}

Address for Correspondence: Dr. Mini John, Associate Professor, Department of Paediatrics, P K Das Institute of Medical Sciences, Vaniamkulam, Ottapalam, Palakkad, Kerala. Email: drminicherian@gmail.com

\begin{abstract}
Background: World Health Organization refers obesity as a global epidemic including children and adults. Low levels of physical activity, TV watching, and unhealthy food habits are risk factors for overweight and obesity in children. Objective: To study the association between eating habits and physical activities and the risk of obesity in school children in Thrissur District, Kerala. Materials and Methods: 1610 school children of the age group 5-10 years from 5 schools of rural and urban regions were selected by purposive sampling method. Pre-designed and pre-tested questionnaire was used to elicit the dietary history and physical activity. Height and weight were measured and BMI was calculated. Overweight and obesity were determined. Students who had BMI for age between $85^{\text {Th }}$ and $95^{\text {Th }}$ percentile of reference population were considered as overweight and BMI for age $>95^{\mathrm{Th}}$ percentile of reference population were considered as obese. Results: The prevalence of obesity is found to be $3.3 \%$ and that of overweight is $4.8 \%$ in the study group. The prevalence of obesity is $4.47 \%$ and $1.98 \%$ in urban and rural school children respectively. Frequency of intake of fried foods, chocolates, Play hours $<1 \mathrm{hr}$ and transport to school by vehicle has a significant influence on BMI. Conclusion: The prevalence of obesity and overweight (BMI $>85$ th Percentile) is significantly higher in urban school children compared to rural school children .Physical inactivity and increased intake of high calorie foods are the main causes for high prevalence.
\end{abstract}

Key words: Obesity; Overweight, Risk factors, Urban

\section{Introduction}

Obesity is one of the major problems affecting children and adolescents and is a universal nutritional concern. Today, obesity is found in many countries where the major nutritional disorder was malnutrition-[1]. An increase in the prevalence of childhood obesity is associated with many potential medical complications in adulthood like hypertension, atherosclerosis , diabetes mellitus, dyslipidemia, sleep apnoea, and osteoarthritis [2]In the last two decades, the prevalence of obesity increased twice in children and tripled in adolescents in the USA. The increase in childhood and adolescent obesity has resulted in an increase in obesity and overweight in adults. It has a public health consequence as $80 \%$ of overweight children become

Manuscript received: $14^{\text {th }}$ Feb 2016

Reviewed: $22^{\text {nd }}$ Feb 2016

Author Corrected; $4^{\text {th }}$ March 2016

Accepted for Publication: $18^{\text {th }}$ March 2016 overweight adults. Directed sessions that emphasize healthy eating and exercise habits for children and their family results in good health in these patients. Evaluation of obesity in childhood is important due to several reasons. As it helps in preventing obesity and it prevents progression of disease which is associated with obesity in adulthood. The present study was designed to determine risk factors for overweight and obesity and was to investigate the differences in food consumption and physical activity among school children.

\section{Materials and Methods}

This study was a cross - sectional study conducted in five schools from Thrissur city ( 3 rural and 2 urban). These schools were selected by using purposive sampling method keeping in view of operational 
feasibility. The sample size was calculated considering the prevalence of obesity in children as $6 \%$.

Study population (n): 1610 children of both sexes between age group of 5-10 years from selected schools.

Inclusion criteria: All students from selected schools in the specific age group, who are willing to participate in the study.

\section{Exclusion criteria}

1. Those children were absent and whose parents were not willing to give consent.

2. Children on chronic steroid therapy.

3. Children had any chronic systemic disease

\section{Study variables}

1. Socio-demographic variables- age, sex, history of any medical illness in the child, food habits, hours of physical activity (exercise/play), time spent on television/computer and relevant personal details and medical history of Family members.

2. Anthropometric measurements -

- Weight - The body weight was measured to a nearest $0.1 \mathrm{~kg}$ using a weighing scale (Libra weighing machine).

- Height - The height was measured to nearest $0.1 \mathrm{~cm}$ by using a non stretchable measuring tape, which was fixed to the wall vertically using cellophane tape, and by making the child stand with heels, buttocks, shoulders and occiput in apposition with the wall, taking care that there is no bending of knees.

- Waist circumference - was measured with a non stretchable tape, at the midpoint between the 12th rib and the iliac crest, to the nearest $0.1 \mathrm{~cm}$, in a standing position during end-tidal expiration.

3. Blood pressure - Blood pressure recording was done by using appropriate cuff size and a standard mercurial sphygmomanometer.

4. General physical examination

Data Collection Procedure: Consent for data collection and examination were obtained from school authorities (principal and PTA) prior to study. Information regarding the study and the consent form was send to all parents through school, along with a questionnaire. A semi-structured pre-tested questionnaire was given to each student with the help of class teacher and was asked to get filled by parents at home. Questionnaire included information regarding demographic details (name, age sex, address, religion history of any medical illness in the child, food habits, hours of physical activity (exercise/play) time spent on television/computer and relevant personal details. The questionnaire was a validated one, prepared after consultation with experts in the health and community level. As far as possible, the free time were used for this study, so that their routine classes were unaffected. The age of children was verified from school records. Children were explained about study in their local language (Malayalam). On obtaining parental informed consent, these children were subjected to, Blood pressure recording and general physical examination and anthropometric measurements of weight, height, and waist circumference.

Height percentiles were determined with Stature-for-age charts for both gender developed by Centers for Disease Control (CDC) [3]. BMI was calculated with the formula, weight in kilograms divided by square of height in meters; $\mathrm{kg} / \mathrm{m} 2$, and BMI percentiles were determined by BMI growth charts for age and gender developed by Centers for Disease Control (CDC)][4]. Blood pressure percentiles were determined by Blood pressure percentiles charts adjusted for age, gender, and height percentile developed by the National Heart Lung and Blood Institute [5].

Data management: Data collected were coded properly and entered in Excel Spreadsheet (Microsoft Excel 2007) and appropriate data checking measures were used for ensuring quality of data. Data analysis was done by SPSS software Chi-square test was used to find out the prevalence and compare the variables. $P$ value $<0.05$ was considered to be statistitically significant.

Ethical consideration: a. The study protocol was submitted for institutional ethical committee approval And approval was obtained.

b. School authorities and Parent Teachers Association (PTA) were informed prior to the study and approval obtained.

c. Consent was obtained from parents prior to data collection and examination.

\section{Results}

1610 school children of the age group 5-10 years from rural and urban schools were subjected to BP recording and anthropometric measurements after getting informed consent and questionnaire about food habits and physical activity 
answered. The prevalence of obesity is found to be $3.3 \%$ and that of overweight is $4.8 \%$ in the study group. The prevalence of obesity is $4.47 \%$ and $1.98 \%$ in urban and rural school children respectively Frequency of intake of fried foods and chocolates, Play hours $<1 \mathrm{hr}$ and transport to school by vehicle has a significant influence on BMI.

Table 1: Prevalence of obesity and overweight based on agglomeration area

\begin{tabular}{|l|l|l|l|l|l|l|l|}
\hline \multicolumn{2}{|c|}{} & Obese & $\begin{array}{l}\text { Over- } \\
\text { weight }\end{array}$ & Normal & $\begin{array}{l}\text { Under- } \\
\text { weight }\end{array}$ & Total & $\begin{array}{l}\text { Significance } \\
\text { (p value) }\end{array}$ \\
\hline \multirow{3}{*}{ School } & $\begin{array}{l}\text { Rural } \\
(\%)\end{array}$ & $15(1.98 \%)$ & $13(1.71 \%)$ & $357(47.04 \%)$ & $374(49.28 \%)$ & 759 & 0.0001 \\
\cline { 2 - 8 } & $\begin{array}{l}\text { Urban } \\
(\%)\end{array}$ & $38(4.47 \%)$ & $65(7.64 \%)$ & $554(65.10 \%)$ & $194(22.8 \%)$ & 851 & \\
\hline
\end{tabular}

Other important point to be noted is prevalence of underweight in rural area is $49.28 \%$ whereas in urban area it is $22.8 \%$.

This is highly statistically significant with $\mathrm{p}$ value $<0.05$ and Chi-square of 139.49

Table 2: Comparison of BMI percentile based on intake of oil

\begin{tabular}{|l|l|l|l|l|l|}
\hline & Obese & Overweight & Normal & Underweight & $\begin{array}{l}\text { Significance } \\
\text { (p value) }\end{array}$ \\
\hline Coconut oil & $44(83.02 \%)$ & $66(84.62 \%)$ & $830(91.11 \%)$ & $530(93.31 \%)$ & \\
\hline Sunflower oil & $1(1.89 \%)$ & $1(1.28 \%)$ & $8(0.88 \%)$ & $9(1.58 \%)$ & 0.004 \\
\hline Palm oil & $5(9.43 \%)$ & $6(7.69 \%)$ & $37(4.06 \%)$ & $9(1.58 \%)$ & \\
\hline Others & $1(1.89 \%)$ & $0(0 \%)$ & $3(0.33 \%)$ & $1(0.18 \%)$ & $12(2.11 \%)$ \\
\hline $\begin{array}{l}\text { Coconut \& } \\
\text { Sunflower oil }\end{array}$ & $2(3.77 \%)$ & $1(1.28 \%)$ & $8(0.88 \%)$ & $7(1.23 \%)$ & $0(0 \%)$ \\
\hline $\begin{array}{l}\text { Coconut oil \& } \\
\text { Palm oil. }\end{array}$ & $0(0 \%)$ & $4(5.13 \%)$ & $24(2.63 \%)$ & $1(0.11 \%)$ & \\
\hline $\begin{array}{l}\text { Coconut, } \\
\text { Sunflower \& Palm } \\
\text { oil. }\end{array}$ & $0(0 \%)$ & $0(0 \%)$ & & $\mathbf{5 6 8}$ & \\
\hline Total & $\mathbf{5 3}$ & $\mathbf{7 8}$ & $\mathbf{9 1 1}$ & & \\
\hline
\end{tabular}

The Chi-square value viz. 37.52 was found to be highly significant ( $\mathrm{p}$ value $=0.004$ ). The intake of coconut oil was more among underweight children (93.31\%), followed by children with normal BMI $(91.11 \%)$ and was relatively poorer among overweight and obese children. The intake of other oils among the subjects in general was relatively uncommon. It may be concluded that mere intake of any sort of oil does not influence obesity

Table 3: Comparison of BMI percentile based on frequency of meat intake

\begin{tabular}{|l|l|l|l|l|l|}
\hline & Obese (\%) & $\begin{array}{l}\text { Overweight } \\
(\mathbf{\%})\end{array}$ & Normal (\%) & $\begin{array}{l}\text { Underweight } \\
(\%)\end{array}$ & $\begin{array}{l}\text { Significance (p } \\
\text { value) }\end{array}$ \\
\hline Daily & $0(0 \%)$ & $3(3.85 \%)$ & $16(1.76 \%)$ & $4(0.70 \%)$ & \\
\cline { 1 - 4 } Weekly & $24(45.28 \%)$ & $42(53.85 \%)$ & $387(42.48 \%)$ & $229(40.32 \%)$ & \multirow{2}{*}{0.10} \\
\cline { 1 - 3 } Monthly & $26(49.06 \%)$ & $30(38.46 \%)$ & $475(52.14 \%)$ & $316(55.63 \%)$ & \\
\cline { 1 - 4 } Nil & $3(5.66 \%)$ & $3(3.85 \%)$ & $33(3.62 \%)$ & $19(3.35 \%)$ & \\
\hline Total & 53 & 78 & 911 & 568 & \\
\hline
\end{tabular}

Based on the cross tabulation of the intake of vegetarian/non-vegetarian foods with BMI percentile (Chi-square value 0.252 ( $\mathrm{p}$ value $>0.05$ ) were not significant. 
Figure 1: Comparison of BMI percentile based on frequency of intake of fried food

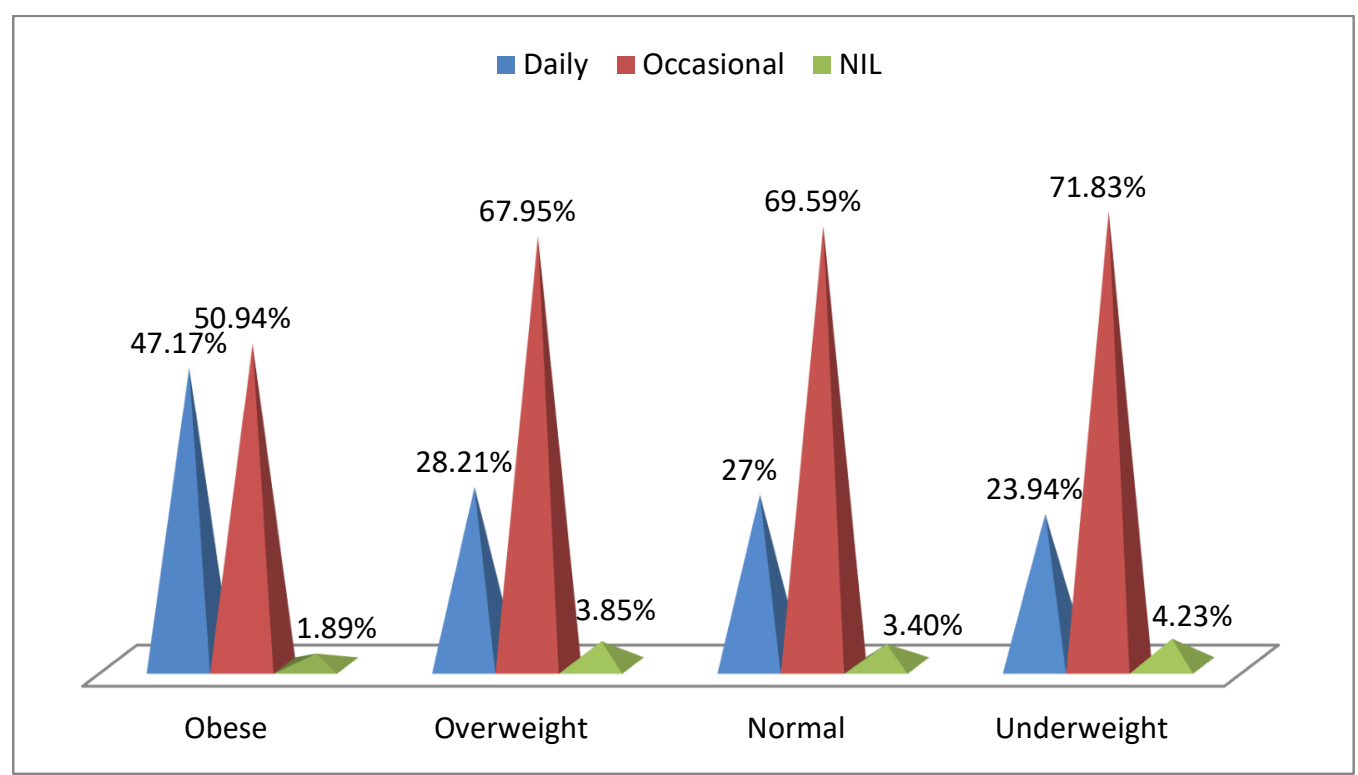

Frequency of intake of fried food significantly influenced BMI. The Chi-square value of 14.25 and p value of 0.02 is significant at 95 percent confidence interval. Daily consumption of fried foods among $47.17 \%$ of the subjects in the obese category was noticed

Figure-2: Comparison of BMI based on hours of play

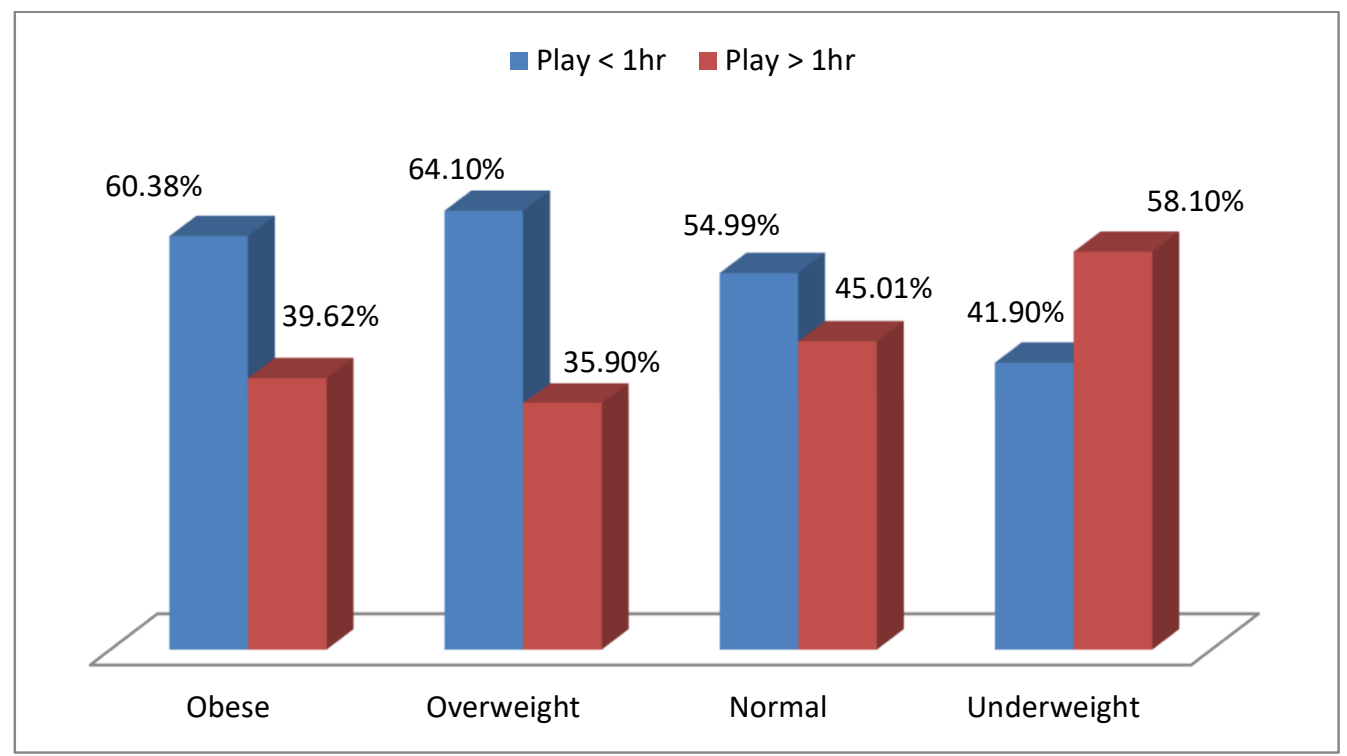

Physical activity denoted by hours of play has a significant influence on BMI. More than $60 \%$ of subjects in obese and overweight group have play hours less than 1 hour. This is found to be highly significant (Chi-square value is 32.49) (p value is 0.05$)$.

Table 4: Comparison of BMI percentile based on mode of transport to school

\begin{tabular}{|c|c|c|c|c|c|}
\hline & Obese (\%) & $\begin{array}{l}\text { Overweight } \\
(\%)\end{array}$ & Normal (\%) & $\begin{array}{l}\text { Underweight } \\
(\%)\end{array}$ & $\begin{array}{l}\text { Significance (p } \\
\text { value) }\end{array}$ \\
\hline Walking & $3(5.66 \%)$ & $9(11.54 \%)$ & $98(10.76 \%)$ & $103(18.13 \%)$ & \multirow{3}{*}{0.01} \\
\hline Vehicle & $50(94.34 \%)$ & $69(88.46 \%)$ & $813(89.24 \%)$ & $465(81.87 \%)$ & \\
\hline Total & 53 & 78 & 911 & 568 & \\
\hline
\end{tabular}


Another measure of physical activity, mode of transport to school has a significant influence on BMI. Nearly $95 \%$ of subjects in obese group go to school in a vehicle. This is found to be statistically significant (p value $<0.05)($ Chi-square is 19.59).

Table 5: Comparison of BMI percentile based on screen time

\begin{tabular}{|l|l|l|l|l|l|}
\hline & Obese (\%) & $\begin{array}{l}\text { Overweight } \\
(\%)\end{array}$ & Normal (\%) & $\begin{array}{l}\text { Underweight } \\
(\%)\end{array}$ & $\begin{array}{l}\text { Significance (p } \\
\text { value) }\end{array}$ \\
\hline $\begin{array}{l}\text { Screen Time } \\
<1 \mathrm{hr}\end{array}$ & $26(49.06 \%)$ & $46(58.97 \%)$ & $470(51.59 \%)$ & $283(49.82 \%)$ & \\
\hline $\begin{array}{l}\text { Screen Time } \\
>1 \mathrm{hr}\end{array}$ & $27(50.94 \%)$ & $32(41.035 \%)$ & $441(48.48 \%)$ & $285(50.18 \%)$ & 0.48 \\
\hline Total & $\mathbf{5 3}$ & $\mathbf{7 8}$ & $\mathbf{9 1 1}$ & $\mathbf{5 6 8}$ & \\
\hline
\end{tabular}

Screen time has no influence on BMI according to this study ( $\mathrm{p}$ value $>0.05$ ) (Chi -square value is 2.47).

Table 6: Comparison of BMI percentile based on family income

\begin{tabular}{|c|c|c|c|c|c|}
\hline & Obese (\%) & $\begin{array}{l}\text { Overweight } \\
(\%)\end{array}$ & Normal (\%) & $\begin{array}{l}\text { Underweight } \\
(\%)\end{array}$ & $\begin{array}{l}\text { Significance (p } \\
\text { value) }\end{array}$ \\
\hline$>20,000$ & $26(49.06 \%)$ & $46(58.97 \%)$ & $384(42.15 \%)$ & $138(24.30 \%)$ & \multirow{5}{*}{0.01} \\
\hline $10,000-19,999$ & $15(28.30 \%)$ & $19(24.36 \%)$ & $199(21.84 \%)$ & $103(18.13 \%)$ & \\
\hline $5,000-9,999$ & $4(7.55 \%)$ & $2(2.56 \%)$ & $109(11.96 \%)$ & $92(16.20 \%)$ & \\
\hline$<4,999$ & $8(15.09 \%)$ & $11(14.10 \%)$ & $219(24.04 \%)$ & $235(41.37 \%)$ & \\
\hline Total & 53 & 78 & 911 & 568 & \\
\hline
\end{tabular}

Family income has a strong influence on BMI. It is noted that nearly $80 \%$ of subjects in obese group and overweight group have family income more than ten thousand rupees/month. Conversely more than $40 \%$ of subjects in underweight group have a family income of less than five thousand rupees/month. This is found highly statistically significant ( $\mathrm{p}$ value $<0.05$ ) with Chi-square value 107.62 .

From this study it is clearly noted that Parent's education and family income is directly proportional to increased incidence of obesity in their children. Mother's education has a strong influence on BMI. It is noted that more than $65 \%$ of subjects in obese group and overweight group have mother's whose education qualification is above graduation. Conversely more than $40 \%$ of subjects in underweight group have mother's whose education qualification is school education. This is found to be highly statistically significant ( $p$ value $<0.05$ ) with Chi-square value 88.24.

\section{Discussion}

Prevalence rates of obesity is between 4 to 30 per cent are reported across different regions in India [6][7][8]. The key to success in tackling the problem of obesity now lies in understanding, measuring and altering this "obesogenic" environment. Evidence from the Cardiovascular Risk in Young Finns study indicates that persistent inactivity in childhood linked to obesity in adulthood [9] in developed countries differences in physical activity with sex and age in children has been reported specifically. The Health and Behaviour of School Children (HBSC) survey conducted in 20 European countries highlighted that in general, girls were less active than boys and the time spent in physically inactive behaviours increased with age [10]. Evidence-based research indicate that exercise reduces adiposity in both overweight and normal and improves cardiovascular health and wellness, improves attention and memory and thereby the school performance [11]. Olympic Committee recognizes that a reduction of screen time - computer games would bring social and health benefits in the community [12]. Factors determining physical activity at an early age are sociocultural and environmental. A recent OECD study shows that the percentages of overweight adolescents has increased worldwide both developing and developed countries [13]. Despite of the importance of physical activity, the ignorance regarding its prescription remains high even if it appears to be vital for less than 6 year old children for trying to avoid adult overweight and obesity. In a nationally representative 
study in the USA [14], children who were physically inactive or the most television viewing tended to be overweight. Among children from Mexico City, obesity was decreased by $10 \%$ per hour of moderate-tovigorous physical activity per day and increased by $12 \%$ per hour of screen time[15]. Television viewing is thought to promote weight gain by displacing physical activity . Children seem to passively consume huge amounts of fried and energy dense foods while watching television and television advertising could negatively affect food intake at other times of the day [16]. Association of BMI with duration of physical activity was studied. Physical activity denoted by hours of play has a significant influence on BMI. More than $60 \%$ of subjects in obese and overweight group have play hours less than 1 hour. Similar to BMI, Physical activity also has a significant influence on Blood pressure. More than $60 \%$ of subjects in hypertensive and pre-hypertensive group have play hours less than 1 hour. This is found to be highly statistically significant. Another measure of physical activity mode of transport to school has a significant influence on BMI. Nearly $95 \%$ of subjects in obese group go to school in a vehicle (Chi-square value is 32.49) ( $\mathrm{p}$ value is 0.001 ). In this study screen time and times spent on tuition, both this parameters had no influence on BMI. The difference in this study may be due to the difference in age group. Children approaching adolescent age group spent more time on television; similarly children approaching higher classes spent more time on tuition, this may be one of the causes of increasing obesity as age increases". Obesogenic schools and extra Tuitions are important factor for obesity. In India there is intense competition for admissions to schools and colleges with extra tuitions right from nursery levels. No play time for them. Some schools do not have any play grounds at al limited play areas, due to unsafe roads .Children are discouraged from walking or cycling to school. As against food as rewards, ironically exercise is meted as a punishment. In May 2004, a report by the International Obesity Taskforce (IOTF) to the World Health Organization (WHO) showed examples of problematic social trends that believed to cause childhood obesity[17].The endocrinological society clinical practical guidelines recommends that each school should provide at least $60 \mathrm{~min}$ of moderate exercise daily in all grades[18]. Canadian Paediatric Society and the American Academy of Paediatrics recommend children not to spent two hours daily in sedentary activities. Findings of epidemiological studies show not much association between dietary fat and obesity in children and young adults [19]. The difference in this study may be due to; the prevalence of intake of coconut oil in the study area is so high that, it alone cannot be assessed as a risk factor. Moreover more than mere intake of type of oil, amount of intake is also important, which was not assessed in this study. Fast food typically contains high fat, sugar preservatives and additives additionally, these foods tend to be low in fibre, micronutrients, and antioxidants: leads to cardiovascular disease and diabetes, [20] in this study the frequency of intake of chocolates influenced BMI and is found to be significant. This shows that high glycemic index foods, such as chocolates has direct influence on obesity. Many other studies also have suggested that a high glycemic index diet has been linked with risk for central adiposity, cardiovascular disease, and type 2 diabetes [21] in adults. In this study the frequency of intake of fried food significantly influenced BMI. Daily consumption of fried foods among $47.17 \%$ of the subjects in the obese category was noticed. Fried foods, in the form of fast foods have become a routine diet in children which increase obesity among them. Research has shown that most commercials shown during children's television viewing are food products and that most foods advertised are of high energy density and poor nutritional quality [22]. Parent's education and family income is directly proportional to increased incidence of obesity and overweight in their children. Conversely it is also noted that low parental education and family income has lead to underweight in their children. It may be that parents having higher education are having higher family income, so these may not be considered as two different risk factors. In transitional economies such as in India, obesity and malnutrition often coexist and produce increased burden on the economy of our country

\section{Limitations of this study}

1. The food habits were assessed based on frequency of consumption from the child's memory.

2. Physical activity was recorded as told by the children, no observation was done.

\section{Conclusion}

Frequency of intake of fried foods and chocolates has significant influence on BMI. Play hours $<1 \mathrm{hr}$ and transport to school by vehicle has a significant influence on BMI .High Parental education and high family income has significant influence on BMI. Government should take appropriate measure regarding control of food-related advertisement shown on television. Through parental education and counselling of urban community we can prevent over weight and obesity. 
Parents are the decision makers and role models for their children. They can modify their food habits and physical activity pattern. Meal time is very short in our schools by increasing meal time children have more time to consume healthier foods, offering fresh fruits and vegetables and avoiding high fat, sweetened snacks during the school day, developing an approved list of school snacks to be offered at school events, and using teachers as role models are just some of the ideas to create a healthy school environment .It is now widely realized that increasing physical activity and decreasing sedentary behaviour should be the major aims at preventing and treating overweight and obesity in young people [23].

\section{References}

1. De Onis M, Blössner M. Prevalence and trends of overweight among preschool children in developing countries. Am J Clin Nutr. 2000 Oct;72(4):1032-9.

2. Sharma A, Sharma K, Mathur KP. Growth pattern and prevalence of obesity in affluent schoolchildren of Delhi. Public Health Nutr. 2007 May;10(5):485-91.

3. Stature- for-age charts for both gender developed by National Centre for Health Statistics in collaboration with the National Center for Chronic Disease Prevention and Health Promotion (2000).Website: www.cdc.gov/growthcharts/data/set2clinical/cj41c071.p df.

4. BMI growth charts for age and gender developed by National Centre for Health Statistics in collaboration with the National Center for Chronic Disease Prevention and Health Promotion (2000). Website: www.cdc.gov/growthcharts/data/set2clinical/cj41c073.p df .

5. Blood pressure percentiles charts adjusted for age, gender, and height percentile developed by the National Heart Lung and Blood Institute.Website: http://www.nhlbi.nih.gov/guidelines/hypertension/child _tbl.pdf.

6.Ramachandran A, Snehalatha C, Vinitha R, Thayyil M, Kumar CK, Sheeba L, Joseph S, Vijay V. Prevalence of overweight in urban Indian adolescent school children. Diabetes Res Clin Pract. 2002 Sep;57(3):185-90.

7. Kapil U, Singh P, Pathak P, Dwivedi SN, Bhasin S. Prevalence of obesity amongst affluent adolescent
Funding: No Funding

Conflict of Interest: The authors declare no conflict of Interest.

\section{Acknowledgement}

Dr Johny Vincent,

Professor and HOD, Jubilee Mission Medical College $\&$ Research institute.

Dr Vinod Jacob Cherian, Professor, Department of Paediatrics, Jubilee Mission

Medical College \& Research institute.

Dr Sanjeev Kumar, Associate Professor

Department of Paediatrics, Jubilee Mission Medical College \& Research Institute.

school children in delhi. Indian Pediatr. 2002 May;39(5):449-52.

8. A.G. Unnithan, S. Syamakumari: Prevalence of Overweight, Obesity and Underweight among School Going Children in Rural and Urban areas of Thiruvananthapuram Educational District, Kerala State (India). The Internet Journal of Nutrition and Wellness. 2008 Volume 6 Number 2.DOI: 10.5580/fcf

9. Yang X, Telama R, Viikari J, Raitakari OT. Risk of obesity in relation to physical activity tracking from youth to adulthood. Med Sci Sports Exerc. 2006 May;38(5):919-25.

10. Roberts C. Currie C, Morgan A, Smith R, Settertobulte W, Samdal O, Rasmussen VB, editors. Young people's health in context: Health behavior in school-aged children (HSBC) study: International report from the 2001/2002 survey, Geneva: World Health Organization; 2004

11. Strong WB, Malina RM, Blimkie CJ, Daniels SR, Dishman RK, Gutin B, Hergenroeder AC, Must A, Nixon PA, Pivarnik JM, Rowland T, Trost S, Trudeau F. Evidence based physical activity for school-age youth. J Pediatr. 2005 Jun;146(6):732-7.

12. International Olympic Committee. Final Declaration, 13th World Sport for All Congress. Jyväskylä, Finland .17 June 2010.

13. Organization for Economic Co-operation and Development. Obesity and the Economics of Prevention: Fit not Fat. Paris: OCDE; 7-8 October, 2010. 
14. Andersen RE, Crespo CJ, Bartlett SJ, Cheskin LJ, Pratt M. Relationship of physical activity and television watching with body weight and level of fatness among children: results from the Third National Health and Nutrition Examination Survey. JAMA. 1998 Mar 25;279(12):938-42.

15. Hernandez B. Gortmaker SL. Colditz GA, Peterson KE. Laird NM. Parra-Cabrera S. Association of obesity with physical activity, television programs and other forms of video viewing among children in Mexico City. Int J Obes Relat Metab Disord 1999 Aug; 23(8): 84554.

16. Robinson TN. Does television cause childhood obesity? JAMA. 1998 Mar 25;279(12):959-60.

17. Lobstein T, Baur L, Uauy R; IASO International Obesity TaskForce. Obesity in children and young people: a crisis in public health. Obes Rev. 2004 May;5 Suppl 1:4-104.

18. August GP, Caprio S, Fennoy I, Freemark M, Kaufman FR, Lustig RH, Silverstein JH, Speiser PW, Styne DM, Montori VM; Endocrine Society. Prevention and treatment of pediatric obesity: an endocrine society clinical practice guideline based on expert opinion. J Clin Endocrinol Metab. 2008 Dec;93(12):4576-99. doi: 10.1210/jc.2007-2458. Epub 2008 Sep 9.

19. Atkin LM, Davies PS. Diet composition and body composition in preschool children. Am J Clin Nutr. 2000 Jul;72(1):15-21.

20. Ludwig DS, Pereira MA, Kroenke CH, Hilner JE, Van Horn L, Slattery ML, Jacobs DR Jr. Dietary fiber, weight gain, and cardiovascular disease risk factors in young adults. JAMA. 1999 Oct 27;282(16):1539-46.

21. Hu FB, van Dam RM, Liu S. Diet and risk of Type II diabetes: the role of types of fat and carbohydrate. Diabetologia. 2001 Jul;44(7):805-17.

22. Borzekowski DL, Robinson TN. The 30-second effect: an experiment revealing the impact of television commercials on food preferences of preschoolers. J Am Diet Assoc. 2001 Jan;101(1):42-6.

23. Epstein LH, Paluch RA, Consalvi A, Riordan K, Scholl T. Effects of manipulating sedentary behavior on physical activity and food intake. J Pediatr. 2002 Mar;140(3):334-9.

\section{How to cite this article?}

John M, Nihaz NK, Jacob Cherian V, Physical activity, sedentary behaviours and eating habits among school children in keralz: Int J Pediatr Res 2016;3(3):168-175. doi:10.17511/ijpr.2016.i03.06. 